\title{
Outcomes and technique of robotic diaphragm plication
}

\author{
Lana Schumacher, Danjing Zhao \\ Division of Thoracic Surgery, Department of Surgery, Massachusetts General Hospital, Boston, MA, USA \\ Correspondence to: Division of Thoracic Surgery, Department of Surgery, Massachusetts General Hospital, Boston, MA 02114, USA. \\ Email: Lschumacher2@mgh.harvard.edu.
}

Submitted Feb 20, 2020. Accepted for publication Aug 07, 2020.

doi: 10.21037/jtd-2019-rts-01

View this article at: http://dx.doi.org/10.21037/jtd-2019-rts-01

Diaphragm paralysis is a known cause of dyspnea. Diaphragm plication operation is a recognized treatment of diaphragm paralysis. Traditionally, this operation was performed through an open thoracotomy. In modern times, advances in minimally invasive surgical technologies have allowed diaphragm plication to be performed with much less surgical trauma to allow for quicker recovery.

Several different minimally invasive approaches for diaphragm plication have been described in literature. While there are many reports on outcome and techniques on thoracoscopic or laparoscopic diaphragm plication, few reports on robotic assisted approaches to diaphragm plication. In 2017, Roy et al. (1) published their experience with robot assisted transabdominal diaphragm plication over 3.5 years. A small defect was first made in the center of the paralyzed diaphragm, creating capnothorax that equalizes the chest and abdomen pressure, allowing the paralyzed diaphragm to become loose and floppy. Plication of the diaphragm was then done medially to laterally, with series suture passes from posterior diaphragm to anterior diaphragm. Usually eight passes of suture were required to complete the diaphragm repair. In retrospective review of 22 patients who received the procedure, Roy et al. reported improvement in breathing in $91 \%$ of the patients per patient's report.

Thoracoscopic diaphragm plication has been reported with good functional results in the literature as well. In a 10-year review of their own institutional experience, Taberham et al. (2) reported results on 35 diaphragm plication performed, 22 of which were 3 -port thoracoscopic surgeries, the rest were limited thoracotomies. The authors reported 3 conversions to thoracotomy from thoracoscopic approach. Mean length of stay was 4.5 days. The operations resulted in improvement of symptoms in $86 \%$ of patients with no death, 30-day readmissions or chronic pain. The authors therefore concluded that thoracoscopic plication of diaphragm is feasible and safe.

In addition, after review of 13 articles comparing thoracoscopic approach to open thoracotomies for diaphragm plication, Gazala et al. (3) found that the thoracoscopic approach was able to achieve similar results as thoracotomies in terms of postoperative improvements in pulmonary function tests and symptoms of dyspnea. There was also less complications with the thoracoscopic approach with less mortality, shorter length of stay and less postop chronic pain.

There are some reports on robotic assisted thoracoscopic diaphragm $(4,5)$, which is the technique we use at our institution. Patients are intubated with double lumen left sided endotracheal tube and placed in the left or right lateral decubitus, semi-flexed position. The case usually starts with placing an $8 \mathrm{~mm}$ robotic port along the $5^{\text {th }}$ or the $6^{\text {th }}$ intercostal space just anterior to the scapular tip. This will serve as the camera port. Two additional working ports are then placed, one anterior to the camera port and one posterior about $8-10 \mathrm{~cm}$ apart. The arms can be positioned c loser to $5 \mathrm{~cm}$ apart in a more narrow thorax. Finally, a $4^{\text {th }}$ assistant port is placed anteriorly between the camera port and the most anterior arm (arm 1) along the same intercostal space or one interspace above depending on spacing available (Figure 1). The robot boom is turned $180^{\circ}$ to face the feet and then docked. Interrupted horizontal mattress plicating stitches are then placed along medial aspect of the diaphragm progressing laterally. Plegits are sometimes used to reinforce the knots. Additional rows of plication sutures running anteriorly to posteriorly are sometimes used for further reinforcement to ensure the diaphragm is tightened and flat (Figure 2). After completion 


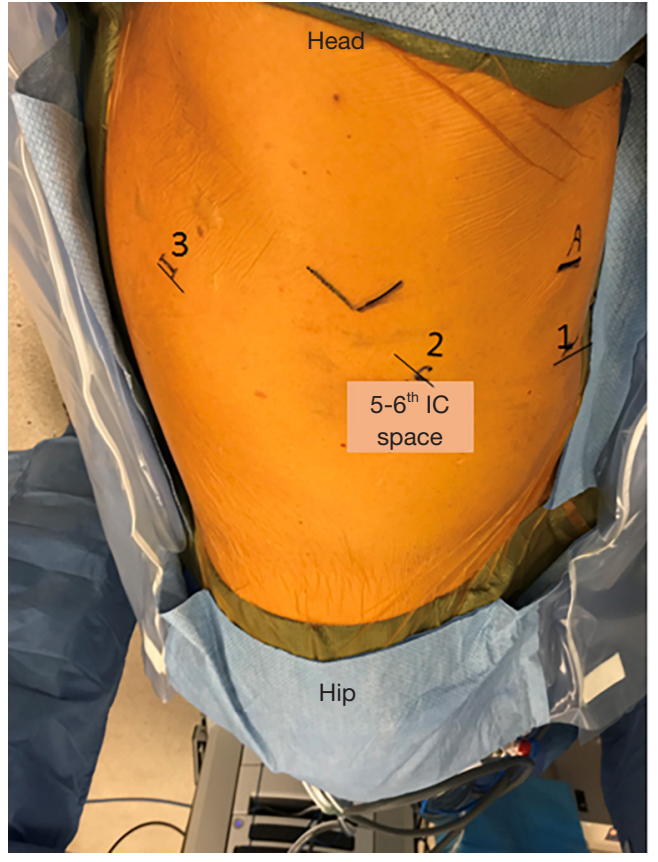

Figure 1 Patient positioning and port placement. The patient is positioned in a lateral decubitus position with the affected side up (left lateral decubitus with right side up in the picture). The robotic boom is driven in from the right side and rotated $180^{\circ}$ to have instruments and camera pointing at the diaphragm. The camera port is placed just anterior to the scapular tip about at the 5-6 intercostal space. Arm 1 is placed anteriorly along the same interspace about $8-10 \mathrm{~cm}$ apart. Arm 3 is placed posteriorly along the interspace about $8-10 \mathrm{~cm}$. IC space = intercostal space; $\mathrm{A}=$ assistant port; Arm 1 = cadiere forceps; Arm 2 = camera; Arm 3 = needle driver.

of plication, a small chest tube drain or Blake drain is placed along the diaphragm below the lung before instruments are removed and skin is closed. Chest tube usually goes to waterseal at midnight on post-op day 0 and is removed when drainage is adequately low, usually post-op day 1 .

14 patients have undergone diaphragm plication at our institution from 2014 to 2018. Causes of paralysis were variable including prior cardiac surgeries, neck surgeries, radiations, thymoma resections, and idiopathic. All patients had ECOG status of 0 or 1 at preoperative evaluation. Average BMI was 33. Average case length was 183 minutes, ranging from 138 to 273 minutes. No cases were converted to open with except of one case that was converted to laparoscopic abdominal approach due to adhesion in left chest from multiple prior cardiac surgeries. With the exception of one patient, 13 of 14 patients had

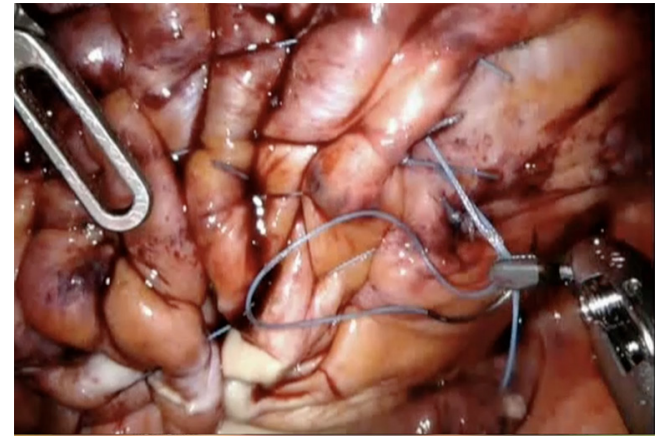

Figure 2 The diaphragm plication after approximately 10-12 rows of horizontal mattress placating sutures.

no major complications with average length of stay of 2 days. One patient's postoperative course was complicated by pneumonia. We did not follow these patients with postoperative pulmonary function tests. However, most were able to return to their baseline ADL and all had improvement in their symptoms at their postoperative visit. Minimal pain was reported at postop visits. Few patients required narcotics medications beyond a few days after surgery.

In summary, diaphragm plication can be safely and effectively performed by minimally invasive surgery, including usage of robotic-assisted technology. We believe the wrist action of the robotic instruments, as well as $\mathrm{CO}_{2}$ insufflation, allowed us to perform these cases minimally invasively in obese patients for which thoracoscopic surgery would have been difficult. Our operating time may be longer because we are a teaching facility, which lengthens the case due to involvement of resident and fellow training. As robotic-assisted surgery become more and more readily available, thoracic surgeons should be aware and familiar with these surgical options. More in depth research is needed to further investigate outcomes and costeffectiveness of robotic-assisted diaphragmatic plication.

\section{Acknowledgments}

Funding: None.

\section{Footnote}

Provenance and Peer Review: This article was commissioned by the Guest Editor (Ghulam Abbas) for the series "Robotic Thoracic Surgery" published in Fournal of Thoracic Disease. The article did not undergo external peer review. 
Conflicts of Interest: Both authors have completed the ICMJE uniform disclosure form (available at http:// dx.doi.org/10.21037/jtd-2019-rts-01). The series "Robotic Thoracic Surgery" was commissioned by the editorial office without any funding or sponsorship. Dr. Schumacher reports personal fees from Intuitive Surgical, outside the submitted work. The authors have no other conflicts of interest to declare.

Ethical Statement: The authors are accountable for all aspects of the work in ensuring that questions related to the accuracy or integrity of any part of the work are appropriately investigated and resolved.

Open Access Statement: This is an Open Access article distributed in accordance with the Creative Commons Attribution-NonCommercial-NoDerivs 4.0 International License (CC BY-NC-ND 4.0), which permits the noncommercial replication and distribution of the article with the strict proviso that no changes or edits are made and the original work is properly cited (including links to both the formal publication through the relevant DOI and the license).
See: https://creativecommons.org/licenses/by-nc-nd/4.0/.

\section{References}

1. Biswas Roy S, Haworth C, Ipsen T, et al. Transabdominal robot-assisted diaphragmatic plication: a 3.5-year experience. Eur J Cardiothorac Surg 2018;53:247-53.

2. Taberham RJ, Raza A, Alzetani A, et al. VATS Plication of the Diaphragm: A Descriptive Observational 10Year Southampton Experience. Innovations (Phila) 2017;12:398-405.

3. Gazala S, Hunt I, Bédard EL. Diaphragmatic plication offers functional improvement in dyspnoea and better pulmonary function with low morbidity. Interact Cardiovasc Thorac Surg 2012;15:505-8.

4. Kwak T, Lazzaro R, Pournik H, et al. Robotic thoracoscopic plication for symptomatic diaphragm paralysis. J Robot Surg 2012;6:345-8.

5. Daniels A, Danau T, Chierchia GB, et al. Robot-assisted thoracoscopic diaphragm plication for symptomatic diaphragm paralysis after cryoballoon ablation. HeartRhythm Case Rep 2019;5:343-6.
Cite this article as: Schumacher L, Zhao D. Outcomes and technique of robotic diaphragm plication. J Thorac Dis 2021;13(10):6113-6115. doi: 10.21037/jtd-2019-rts-01 